\title{
Investigation of the Breeding Mechanism of African Yam Bean [Fabaceae] (Sphenostylis stenocarpa Hochst. Ex. A. Rich) Harms
}

\author{
Daniel B. ADEWALE ${ }^{1 *}$, Adegoke E. ADEGBITE² \\ ${ }^{1}$ Federal University Oye-Ekiti, Department of Crop Science and Horticulture, Ikole-Ekit Campus, Ekiti State, \\ Nigeria; d.adewale@gmail.com (*corresponding author) \\ ${ }^{2}$ Ondo State University of Science and Technology, Department of Biological Sciences, Okitipupa, Nigeria; gokeadegbite@yahoo.co.uk
}

\begin{abstract}
The many reported inherent nutritional potential in African yam bean (Sphenostylis stenocarpa (Hochst. Ex. A. Rich.) Harms) seem to provide platform for the need of its genetic improvement. A good understanding of the breeding system of the crop species is a needed criterion in plant breeding program. Four accessions of African yam bean (AYB) collected from the Genetic Resources Centre of the International Institute of Tropical Agriculture (IITA), Ibadan, Nigeria were grown out in a fifteen plants/accession row on a field at IITA, Ibadan $\left(7.5^{\circ} \mathrm{N}, 3.9^{\circ} \mathrm{E}\right)$, Nigeria. Five pollination mechanisms were investigated as treatments on the four accessions. The four accessions set fruits and seeds in four treatments: plants left to open-pollination (A), plants isolated with fine net mesh (B), artificially selfed flowers (C) and inter-varietal cross-pollination (D). Emasculated flowers which were not pollinated (treatment $\mathrm{E}$ ) produced neither fruit nor seed. Treatment A differed significantly $(\mathrm{P}<0.05)$ from B, likewise C and D. Fruit set percentage was higher in A (19.7-21.2) than B (18.3-18.7). Higher pollination/fertilization success $(46.5 \%)$ was obtained in C compared to $32.3 \%$ in D. More seeds $(88.6 \%)$ were set by self-pollination. The four accessions had a mean selfing rate of $89.8 \%$ and an outcrossing rate of $10.17 \%$. The observed 1:9 allogamy: autogamy in this study could form the basis for developing the breeding strategy for the genetic improvement of AYB via hybridization.
\end{abstract}

Keywords: allogamy; autogamy; emasculation; pollination mechanisms; selfing rate; outcrossing rate

\section{Introduction}

Information on the flowering characteristics and pollination mechanism of African yam bean (AYB) is scarce. However, Frankel and Galum (1977) documented that pre-anthesis self-pollination is common in many cultivated legumes such as: Phaseolus vulgaris, Vigna radiata, Arachis hypogaea, Cajanus cajan, Glycine max, Vicia angustifolia, $V$. sativa and Pisum sativum. These species exhibit autogamy; such that successful pollinationfertilization occurs prior to the time of floret opening, leading to fruits and viable seeds production. This according to Dobrenz and Beetle (1966) is possible because of selfcompatibility within the species. It is noteworthy to uphold here that the breeding system of legumes is not uniquely the same: while high level of out-crossing are reported among the arboreal species, autogamy predominates among the herbaceous leguminous species (Arroyo, 1981; Bawa, 1992). According to Maxted et al. (2004) each species in the genus Vigna exhibits a combination of facultative xenogamy and autogamy. Crane and Walker (1984) speculated that if any pollination agents will be involved in the sexual mode of AYB, they would likely be insects. The predominant species of insect involved in legume pollination are the bees (Tandon et al., 2003; Maxted et al., 2004).

Maxted et al. (2004) affirmed that the importance of breeding system is critical to understanding natural crossing rate, gene flow, pattern of genetic diversity and minimum population size. Therefore, an unambiguous grasp of the pollination mechanism of a species of interest is a necessary primary knowledge for a plant breeder. Dafni (1992) remarked that the basic understanding of the structure, sexuality and phenology of the flower is a pre-requisite for understanding the life cycle as well as the necessary background for any pollination and reproductive biology studies.

Although AYB is an underutilized species, its nutritional profile, relevance in the food culture of the West and Central Africans and its possible contribution to food security made the need for its genetic improvement a necessity (Adewale, 2010). Crop improvement via hybridization is not possible without the knowledge of the 
200

breeding system of the species. However, since breeding mechanism can be predicted from floral morphology (Lush, 1979), the present study in the bid to understanding the breeding system of AYB has proposed the following hypotheses: (i) AYB exhibit autogamy, (ii) AYB exhibit outcrossing and (iii) AYB does not exhibit apomixes. The proportional occurrence of either or all the above breeding systems was investigated and reported in this study.

\section{Materials and Methods}

The pollination mechanism of AYB was determined under the natural field condition as suggested by Dafni, (1992). The land was prepared and seeds of four accessions (TSs16, TSs39, TSs89 and TSs117) were planted on ridges at 1 metre apart. The spacing between rows was also 1 metre. One plant was maintained per hill and each accession had a population of fifteen plants per row. Five plants each were tagged and labeled as A and B in a row. Flowers on the remaining five plants in each row were emasculated and tagged as $\mathrm{C}, \mathrm{D}$ and $\mathrm{E}$ for hand pollination or otherwise.

Label descriptions of the treatments in the study were: 1a)

A - plants left to open- pollination (as shown in Plate

B - a whole plant isolated with fine mesh transparent net (as shown in Plate $1 \mathrm{~b}$ )

C - flowers emasculated and pollinated with pollen from the same plant

D - flowers emasculated and pollinated with pollen from another accession

E - flowers emasculated without pollination

Emasculation and hand pollination was done in the morning following the method of Buishand (1956) and Myers (1996). Forceps were intermittently dipped in Methylated spirit during emasculation to prevent pollen contamination as recommended by Frankel and Galum (1977). The basic protocol of emasculation was carried out on the flowers which received treatments C, D and E. Flower buds with conspicuous purple lateral line along the enclosing end of the standard petal were emasculated in the mornings. Emasculated flowers were bagged for 24 hours. Hand pollination with pollens from the same plant $(C)$ and pollens from another accession (D) was done through rubbing of the dehisced anther on the stigmatic end of the emasculated flowers a day after emasculation. Emasculated flowers tagged $\mathrm{E}$ were not pollinated.

Treatment ratio was estimated for the fruit set percentages (the percentage of the number of fruits to the number of studied flowers at the end of the reproductive cycle) in treatments A and B as the proportion of treatment $\mathrm{B}$ to A. Fruit set and seed set percentage (i.e. $100 \mathrm{x}$ number of seeds per pod/number of locules per pod) as recommended by Dafni (1992) were estimated. Paired t-test statistics was employed to compare the means of the two parameters between treatments $\mathrm{A}$ and $\mathrm{B}$, then $\mathrm{C}$ and $\mathrm{D}$, following Gomez and Gomez (1984).

The Index for Self Incompatibility (ISI) was estimated following Zapata and Arroyo (1978) recommendation as: Fruit set from self-pollination (artificial selfing by hand)/ Fruit set from cross-pollination. The selfing rate $(S)$ was estimated on the seed set percentage following the equation of Charlesworth and Charlesworth (1987) as:

$$
S=\frac{P x-P o}{P x-P s}
$$

where:

$\mathbf{P}_{\mathbf{x}}$ is the seed set percentage value from crossing, $\mathbf{p}_{\mathbf{s}}$ is the seed set percentage value from artificial selfing, and $\mathbf{P}_{\mathrm{o}}$ is the seed set percentage value from open pollination. The out crossing rate was determined by the equation proposed by Karron (1987) as:

\section{$\mathbf{T}=\mathbf{1 - S}$}

where:

$\mathbf{t}$ is the out crossing rate and $\mathbf{S}$ is the selfing rate.

The seeds obtained from the five categories (i.e. A, B, C, $\mathrm{D}$ and $\mathrm{E}$ ) were put into germination test to ascertain their viability and reproductive success as recommended by Dafni (1992).

\section{Results}

Plate $1 \mathrm{a}$ and $\mathrm{b}$ showed two of the five pollination mechanisms. Plate la, i.e. treatment $\mathrm{A}$, has a whole plant left to open pollination while Plate $1 \mathrm{~b}$ which is tagged as treatment $B$ has a whole individual plant isolated with fine transparent mesh net. Flowers in treatment A did advertise and attracted insects especially the bees (Plate 2). However, the flowers in treatment $\mathrm{B}$, did anthesize and advertised but pollinators where prevented from reaching them (See Plate 1b).

Fruit and seed were set in treatments A, B, C and D. The percentage fruit set by the four AYB accessions under open pollination and isolation were presented in Table 1. Fruit set percentage was higher in treatment $\mathrm{A}$ than $\mathrm{B}$. The percentage ranged between 19.7 and 21.2 in $A$ and 18.3 18.7 in B (Table 1). The proportion of treatment B to A ranged between $86.8 \%$ and $92.9 \%$ (Table 1). The number of attempted crosses and the successes made for various crosses were presented in Table 2. Success was recorded in two of the three methods but there was no success when emasculation was not followed up with pollination. Higher success rate (46.5\%) was recorded in artificial selfing, compared to $32.3 \%$ from crosses among different accessions. TSs117 had the highest success percentage $(60.5 \%$ and $33.3 \%)$ for autogamy and allogamy respectively (Table 2).

Table 3 differentiated the means of fruit and seed set percentages among the pollination methods. Fruit and seed set percentage differed significantly $(\mathrm{P}<0.05)$ among treatments $A$ and $B$, then $C$ and $D$. Fruit and seed set percentages were higher in $\mathrm{A}(20.6 \%$ and $88.1 \%)$ than $\mathrm{B}$ (18.5\% and 84.3\%), then in C (44.5\% and 88.6\%) than D $(32.3 \%$ and $82.7 \%)$ respectively (Table 3). Moreover in Table 3 for treatments $C$ and D, high $(82 \%-88 \%)$ seed set percentage for either self or cross-compatibility was further revealed (Table 3).

More seeds (88.6\%) were set when the pollen from the same plant was placed on its own stigma. Moreover, plants left to open pollination equally had a high (88\%) seed set percentage. Seed set by AYB accessions under an isolated condition was third in rank (84.3\%) and the fourth (82.7\%) was from crosses between two different accessions (Table 4). The mean index for self-incompatibility $(1.44 \%)$ was very low among the four accessions with the least $(1.18 \%)$ from TSs39. The four accessions had $89.8 \%$ selfing rate, with the 
highest (97.15\%) in TSs89. The out crossing rate was lowest (2.85\%) in TSs89; TSs16 had the highest (13.7\%) but the mean from the four accessions was $10.17 \%$ (Table 4).

The seeds obtained from the four treatments were put into germination test to ascertain their viability. Table 5 presents the result. The least (70\%) germination percentage occurred in TSs 117 under treatment A. TSs 16 had the least vigor of $65 \%$ under the same condition of pollination (i.e. A). For plants within an enclosed bagging, 100\% germination and vigour was obtained in TSs16, TSs39 and TSs89 (Table 5).
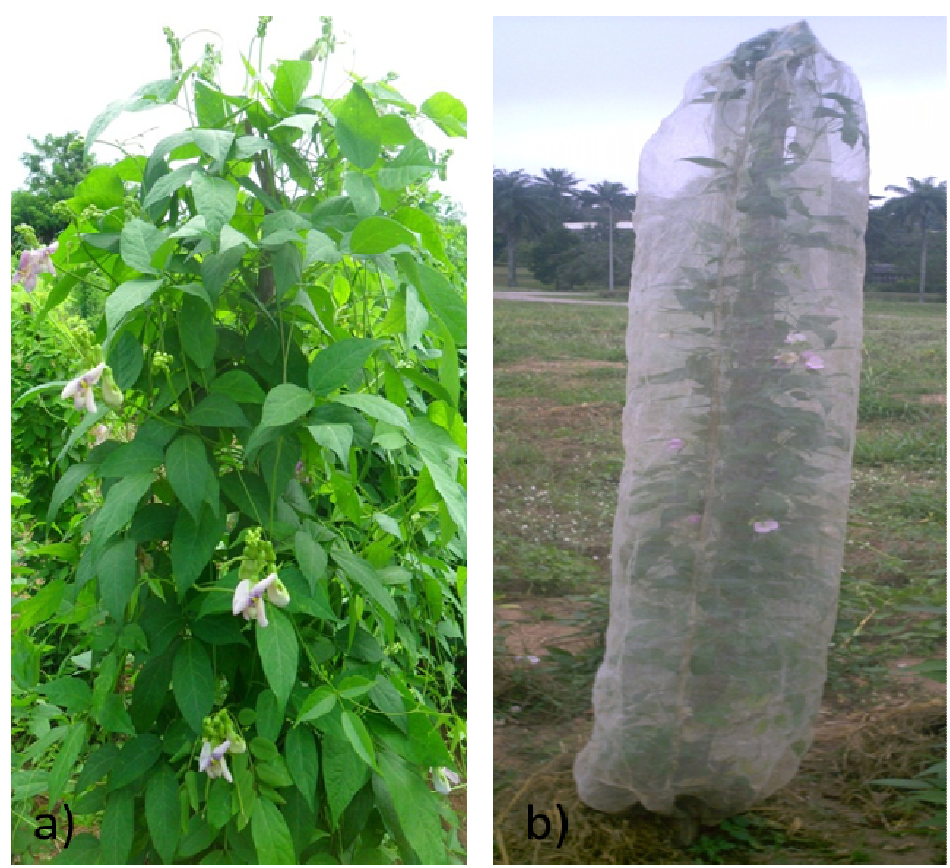

Plate 1. (a) African yam bean left to open pollination, and (b) a whole plant isolated with fine mesh transparent net
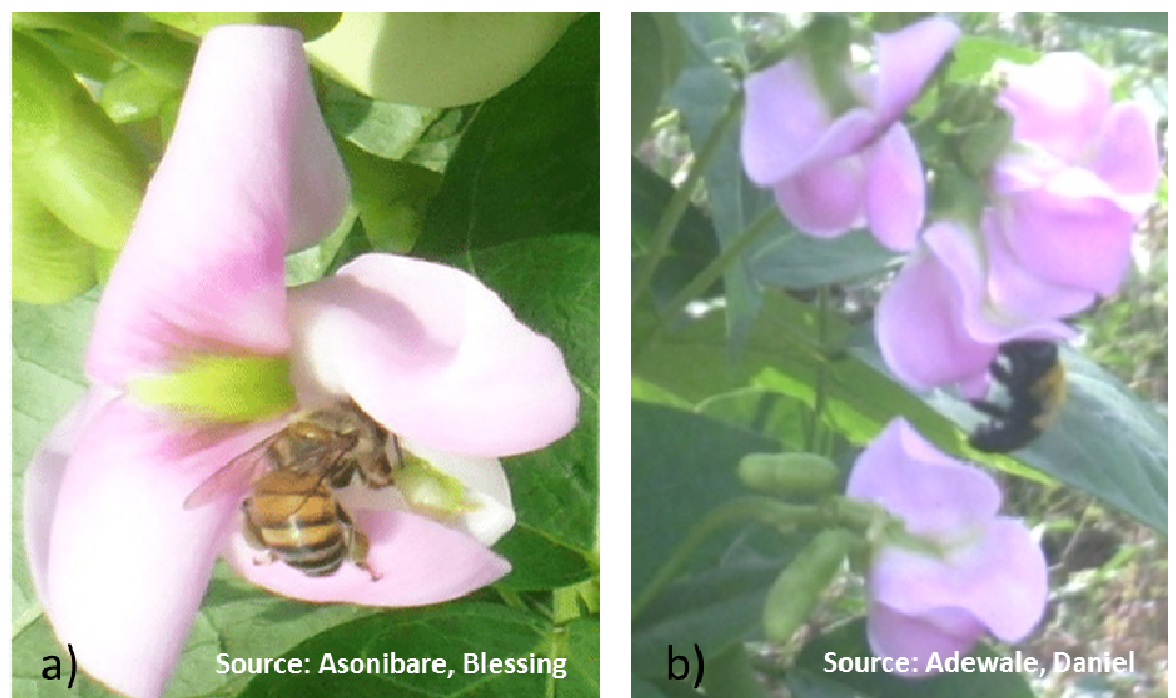

Plate 2. The visit of (a.) honey and (b.) bumble bee (pollinators) to the flowers of African yam bean left to open pollination

Table 1. Fruit set percentage by treatments A and B

\begin{tabular}{ccccc}
\hline & \multicolumn{5}{c}{ Accessions } \\
\hline Treatments & TSs16 & TSs39 & TSs89 & TSs117 \\
A & $21.2 \pm 0.006$ & $20.6 \pm 0.005$ & $20.9 \pm 0.009$ & $19.7 \pm 0.011$ \\
B & $18.4 \pm 0.011$ & $18.4 \pm 0.028$ & $18.7 \pm 0.019$ & $18.3 \pm 0.013$ \\
Treatment Ratio B:A & 86.79 & 89.32 & 89.47 & 92.89 \\
\hline
\end{tabular}

${ }^{*}$ Treatments: A - Open pollinated and B - Selfed (by isolation in bags). 
202

Table 2. Number of attempted crosses, corresponding number and percentages of successes achieved for various pollination method in African yam bean

\begin{tabular}{|c|c|c|c|c|c|c|c|c|c|}
\hline \multirow[b]{2}{*}{ Accessions } & \multicolumn{3}{|c|}{ Artificial Selfing (by hand pollination) } & \multicolumn{3}{|c|}{ Crosses between different Accessions } & \multicolumn{3}{|c|}{ Emasculation without pollination } \\
\hline & $\begin{array}{c}\text { No. of } \\
\text { Attempts }\end{array}$ & $\begin{array}{c}\text { No. of } \\
\text { Success }\end{array}$ & $\begin{array}{c}\% \\
\text { Success }\end{array}$ & $\begin{array}{c}\text { No. of } \\
\text { Attempts }\end{array}$ & $\begin{array}{l}\text { No. of } \\
\text { Success }\end{array}$ & \% Success & $\begin{array}{c}\text { No. of } \\
\text { Attempts }\end{array}$ & $\begin{array}{l}\text { No. of } \\
\text { Success }\end{array}$ & $\begin{array}{c}\% \\
\text { Success }\end{array}$ \\
\hline TSs16 & 45 & 20 & 44.44 & 35 & 11 & 31.43 & 30 & 0 & 0 \\
\hline TSs39 & 39 & 15 & 38.46 & 40 & 13 & 32.50 & 34 & 0 & 0 \\
\hline TSs89 & 40 & 17 & 42.50 & 44 & 14 & 31.82 & 31 & 0 & 0 \\
\hline TSs117 & 38 & 23 & 60.53 & 30 & 10 & 33.33 & 30 & 0 & 0 \\
\hline Mean & 40.50 & 18.75 & 46.48 & 37.25 & 12 & 32.27 & 31.25 & 0 & 0 \\
\hline
\end{tabular}

Table 3. Mean comparison by $\mathrm{t}$-test of the fruit set and seed set percentages among the various pollination methods

\begin{tabular}{cccc}
\hline Parameters & Categories & Mean \pm SE & t-value \\
\hline & A & $20.60 \pm 0.32$ & $7.49^{* *}$ \\
Fruit set percentage & B & $18.45 \pm 0.09$ & $3.12^{*}$ \\
& C & $46.48 \pm 4.83$ & $4.31^{*}$ \\
Seed set percentage & D & $32.25 \pm 0.42$ & \\
& A & $88.10 \pm 1.31$ & $2.42^{*}$
\end{tabular}

* - Significance at $\mathrm{P}=0.05,{ }^{* *}$ - Significance at $\mathrm{P}=0.01$

* Treatments: A - Open pollinated, B - Selfed (by isolation in bags), C - Artificial Selfing (by hand pollination) and D - Crosses between different accessions (by hand pollination).

Table 4. Reproductive biology estimates of four accessions of African yam bean

\begin{tabular}{cccccccc}
\hline \multirow{2}{*}{ Accessions } & \multicolumn{3}{c}{ Seed set percentages (\%) } & \multicolumn{3}{c}{ Reproductive biology estimate (\%) } \\
\cline { 2 - 8 } & Po & IS & Ps & Px & ISI & S & t \\
\hline TSs16 & 91.79 & 89.16 & 92.07 & 90.03 & 1.41 & 13.28 & 87.08 \\
TSs39 & 87.96 & 82.43 & 88.19 & 86.41 & 18 & 12.92 \\
TSs89 & 86.83 & 84.89 & 87.06 & 78.99 & 1.34 & 1.82 & 2.85 \\
TSs117 & 85.80 & 80.81 & 87.13 & 75.24 & 88.81 & 11.19 \\
Mean & 88.10 & 84.32 & 88.61 & 82.67 & 1.44 & 89.83 & 10.17 \\
\hline
\end{tabular}

NB: Px - the value from crosses between two accessions, Ps - the value from selfing by hand pollination, Po - the value from open pollination, IS - the value from isolated whole plant with net bag, ISI - Index for Self Incompatibility, $\mathbf{S}$ - Selfing rate and $\mathbf{t}$ - Out crossing rate

Table 5. The germination and vigour percentages of the seeds of the four accessions of African yam bean obtained from the various treatments

\begin{tabular}{|c|c|c|c|c|c|c|}
\hline Treatments & Accessions & $\begin{array}{c}\text { Total seeds for } \\
\text { germination test }\end{array}$ & $\begin{array}{c}\text { Total germination } \\
\text { at } 10 \text { days }\end{array}$ & $\begin{array}{l}\text { Normal } \\
\text { seedlings }\end{array}$ & $\begin{array}{c}\text { Germination } \\
(\%)\end{array}$ & $\begin{array}{c}\text { Vigour } \\
(\%)\end{array}$ \\
\hline \multirow{5}{*}{ A } & TSs16 & 20 & 15 & 13 & 75 & 65 \\
\hline & TSs39 & 20 & 19 & 17 & 95 & 85 \\
\hline & TSs89 & 20 & 18 & 18 & 90 & 90 \\
\hline & TSs117 & 20 & 14 & 14 & 70 & 70 \\
\hline & TSs16 & 20 & 20 & 20 & 100 & 100 \\
\hline \multirow{3}{*}{ B } & TSs39 & 20 & 20 & 20 & 100 & 100 \\
\hline & TSs89 & 20 & 20 & 20 & 100 & 100 \\
\hline & TSs 117 & 20 & 16 & 16 & 80 & 80 \\
\hline \multirow{4}{*}{$\mathrm{C}$} & TSs16 & 20 & 18 & 18 & 90 & 90 \\
\hline & TSs39 & 20 & 19 & 19 & 95 & 95 \\
\hline & TSs89 & 20 & 18 & 18 & 90 & 90 \\
\hline & TSs117 & 20 & 17 & 17 & 85 & 85 \\
\hline \multirow{4}{*}{$\mathrm{D}$} & TSs16 & 20 & 17 & 17 & 85 & 85 \\
\hline & TSs39 & 20 & 18 & 18 & 90 & 90 \\
\hline & TSs89 & 20 & 18 & 16 & 90 & 80 \\
\hline & TSs117 & 20 & 19 & 16 & 95 & 80 \\
\hline
\end{tabular}

*Treatments: A - Open pollinated, B - Selfed (by isolation in bags), C - Artificial Selfing (by hand pollination) and D - Crosses between different accessions (by hand pollination) 


\section{Discussion}

Fruits and seeds were set when the plants were left to open-pollination. However, as against zero fruit set observed by Chourykaew et al. (2004) for Afgekia sericea (Fabaceae) when pollinators were excluded, African yam bean accessions did anthesize and turned in fruits and viable seeds when pollinators visit were prevented. This revealed that African yam bean exhibits selfing or autogamy. This result however negated the generalized remark by Arroyo (1981) that self-incompatibility was frequently found in Papilionoideae.

In most autogams anther dehiscence and stigma receptivity occurs before or at anthesis (Frankel and Galum, 1977). There are usually developmental inferences on flowers for prospective anthesis or anther dehiscence. Among the notable indicators are: change of colour at the tip of the closing corolla (as observed in Flax, Tobacco and Tomato), increase in flower bud size, protrusion of petals from the calyx, etc. (Frankel and Galum, 1977). An earlier study (by Adewale and Amazue, 2018) identified the stage at which purple line appears along the enclosing end of the standard petal as the peak of floral maturation in African yam bean; however, pollen may not dehisced at this stage. Based on the studied accessions, we recommended emasculation at the notice of the significant purple-line indicator for breeding program through hybridization.

In most cases, breeding through hybridization of crop species had been preceded by emasculation before anthesis (Buishand, 1956; Myers, 1996). Mechanical removal of microsporophyll, differential destruction of spores and induction of male impotence are the means by which selfpollination can be prevented in autogams. Manual emasculation of large flowers entails the excision of unopened anther; this is usually done shortly before the anther dehisces. From this study, emasculation without pollination (within 24hours) did not lead to fruit set. This confirms that apomixes is not a breeding system in African yam bean. Moreover, it also reflect that the timing of stigmatic receptivity in African yam bean is within the notice of the purple-line and probably some hours later; the observed high fruit set among the studied genotypes which received pollen after emasculation seems inferential.

Hand pollination of this species with pollen from the same plant and another accession led to fruit set. The gynoecium of the studied accessions accepted pollens from a range of available accessions. The exhibition of both selfing and out crossing in African yam bean was identified in this study; meaning that some proportion of the crop germplasm will be heterozygous. Before now, many authors (Moyib et al., 2008; Adewale et al., 2012; Ojuederie et al., 2014; Adewale et al. 2015) had indicted the possibility of some degree of heterozygosity in the different studied population. Outcrossing rate of about $10 \%$ was obtained in this study, but Duke (1981) reported a range of $10-15 \%$ for Vigna unguiculata. If the outcrossing rate remains consistent in the species, continuous increase in the quantity of intra-specific diversity and survival of the taxon is assured. Moreover, the high rate of intra-specific crossing success leading to high seed set percentages was worthwhile; subsequent trait improvement through intra-specific hybridization may be less challenging.
Fruit and seed setting varied among the accessions; Ogunbodede (1990) had a similar result among ten cowpea (Vigna unguiculata) genotypes. Moreover, the four breeding systems tested differed significantly in percentages of fruit and seed setting. The comparison of accessions under open pollination with those isolated, and between artificial selfing with crosses (i.e. between two accessions) for fruit and seed set percentages revealed significant differences too. More fruit and seed were set by open-pollination breeding technique than the artificially selfed method. Suso and Rio (2015) noted that improved pollination practices can help support higher yield for a wide range of crop species. The higher pod and seed set in open pollinated breeding mechanism observed in our result may be due to cumulative contribution of natural selfing and entomogamous pollination. Except for pure line breeding stock generation, cultivation of African yam bean without isolation will support its higher pod and grain productivity.

Fruit set percentage resulting from selfing/autogamy in each of the four accessions was $>85 \%$, this seems to reveal that African yam bean is more of a selfer. The significantly higher fruit and seed set in the crosses within the same plant may be suggesting high self-compatibility in the species. The autogamous status of the species would probably have been favoured by its characteristic cleistogamous floral structure.

This study identified the visit of the bumble and honey bees, although the bumble bee were more frequent. The visit of some bee species to the flowers of African yam bean confirmed the earlier assertion of Faegri and Van der Pijl (1979), Tandon et al. (2003) and Maxted et al. (2004) that the papilionaceous flowers are bee-pollinated. As suggested by Johnson and Steiner (2000), the large number of pollinating species frequenting a plant species is not a satisfactory method to measure the degree of specialization. To them, the active pollinators comprise only a very small fraction of the total number of visitors. It is noteworthy to infer that pollinator preference for species is mostly determined by suites of floral characters, usually referred to as pollination syndromes (Faegri and Van der Pijl, 1979; Proctor et al., 1996; Guebitz et al., 2009). Flower color, morphology, fragrance, nectar quality and quantity are in the list of the pollinator syndrome components (Faegri and Van der Pijl, 1979; Brandenburg et al., 2009). Therefore, understanding the differential foraging and pollinating capacity by frequencies of honey and bumble bee on African yam bean would be a necessary investigation.

Nectar production in Butea monosperma according to Tandon et al. (2003) is confined to the period during which the stigma is receptive. Visits by both purple sunbirds and the three-stripe squirrels were correlated with the availability of nectar; hence the reported (Tandon et al., 2003) high degree of geitonogamous pollination in the species. Bee visit to African yam bean flowers coincides with anthesis (a probable peak of stigma receptivity); this may have immensely encouraged outcrossing in the species.

The prospect of the bees which brought foreign pollen was quite significant too; adding as much as $15 \%$ to fruit setting in this study. The present study admitted that the higher and significant fruit set percentage obtained under open pollination may have been due to the visit of the pollinators. The visits of pollinators have been identified to aid fruit and seed setting efficiency in many species (Becerra 
204

and Lloyd, 1992; Sahai, 2009). The observed significant difference for mean fruit and seed set percentages between treatments A and B in this study could be due to the contributory role of the pollinators, whose visit may help to increase the number of fertilized flowers. Since there was spontaneous autogamy, as indicated by fruit set in flowers isolated within a fine-meshed net, our result specify that under open-pollination, pollen load in Sphenostylis stenocarpa was largely autogamous. Pollinator visits adds to pollination and fertilization success in the species, thus increasing pod and seed productivity via both autogamy and allogamy as against sole autogamy.

\section{Conclusions}

Population generation and trait development which is fundamental to crop improvement is not possible without the ascertainment of the breeding system of the crop. The present work was therefore proposed and our research outcome identified the leguminous species to exhibit both autogamy and allogamy in the proportion of 9:1.

\section{Acknowledgements}

This research received no specific grant from any funding agency in the public, commercial, or not-for-profit sectors.

\section{References}

Adewale BD, AmazueEU (2018). Floral maturation indices of African yam bean (Sphenostylis stenocarpa Hochst Ex. A. Rich) harms (Fabaceae). Notulae Scientia Biologicae 10(1):102-106.

Adewale BD (2010). African yam bean: a food security crop? IITA R4D Review 4:5456.

Adewale BD, Dumet DJ, Vroh-Bi I, Kehinde OB, Ojo DK, Adegbite AE, Franco J (2012). Morphological diversity analysis of African yam bean and prospects for utilization in germplasm conservation and breeding. Genetic Resources and Crop Evolution 59:927-936.

Adewale BD, Vroh-Bi I, Dumet DJ, Nnadi S, Kehinde OB, Ojo DK, Adegbite AE, Franco J (2015). Genetic diversity in African yam bean accessions based on AFLP markers: towards a platform for germplasm improvement and utilization. Plant Genetic Resources Characterization and Utilization 13:111-118.

Arroyo MTK (1981). Breeding systems and pollination biology of Leguminosae. In: Polhill RM, Raven PH (Eds). Advances in legume systematics. Proceedings of the International Legume Conference, 1978. Royal Botanic Gardens, Kew, pp 723-769.

Bawa KS (1992). Mating systems, genetic differentiation and speciation in tropical rain forest plants. Biotropica 24:250-255.

Becerra JX, Lloyd DG (1992). Competition dependent abscission of selfpollinated flowers of Phormum tenax (Agavaceae); a second action of self-incompatibility at the whole flower level. Evolution 46:458-469.

Brandenburg A, Dell'Olivo A, Bshary R, Kuhlemeier C (2009). The sweetest thing: Advances in nectar research. Current Opinion in Plant Biology 12:486490.

Buishand T(1956). The crossingofbeans. Euphytica5:41-50.

Charlesworth D, Charlesworth B (1987). Inbreeding depression and its evolutionary consequences. Annual Review of Ecology, Evolution and Systematics18:237-268.

Chourykaew B, Khunwasi C, Boonkerd T, Seelanan T (2004). Floral visitors and fruit set in Afgekia sericea Craib (Fabaceae). The Natural History Journal ofChulalongkorn University 4:3144.

Crane E, Walker P (1984). Pollination directory for world crops. International Bee Research Association (IBRA), London.

Dafni A (1992).Pollination ecology: a practical approach. IRL Press, Oxford.

Dobrenz AK, Beetle AA (1966). Cleistogenes in Danthonia. Journal of Range Management 9:292-296.

Duke JA (1981). Handbook of legume of world economic importance. Plenum Press, New York.

FaegriK, Van der Pijl L (1979). The principles of pollination ecology. Oxford Pergamon, New York

Frakel R, Galum E (1977). Pollination mechanisms, reproduction and plant breeding. Springer-Verlag, Berlin

Gomez KA, Gomez AA (1984). Statistical procedure for agricultural research John Wiley and Sons, New York

Guebitz T, Hoballah ME, Dell'Olivo A, Kuhlemeier C (2009). Petunia as a model system for the genetics and evolution of pollination syndromes. In: Gerats T,StrommerJ(Eds).Petunia. Springer,New York, pp 29-49.

Johnson SD, Steiner KE (2000). Generalization versus specialization in plant pollination systems. Trend in Ecology and Evolution 15:140-143.

Karron JD (1987). A comparison of levels of genetic polymorphism and selfcompatibility in geographically restricted and widespread plant congeners. Evolution and Ecology 1:47-58.

Lush WM (1979). Floral morphology of wild and cultivated cowpeas. Economic Botany 33:442-447.

Maxted N, Mabuza-Diamini P, Moss S, Padulosi S, Jarvis A, Guarino L (2004). An ecogeographic study. African Vigna. International Plant Genetic Resources Institute, Rome, pp 51.

Moyib OK, Gbadegesin MA, Aina OO, Odunola AO (2008). Genetic variation within a collection of Nigerian accessions of African yam bean (Sphenostylis stenocarpa) revealed by RAPD primers. African Journal of Biotechnology 7:1839-1846.

Myers GO (1996). Hand crossing of Cowpea IITA Research Guide 42:1520.

Ogunbodede BA (1990). Reproductive efficiency in cowpea (Vigna unguiculata (L.) Walp) in southwestern Nigeria. Scientia Horticulturae 42:219-224.

Ojuederie OB, Balogun MO, Fawole I, Igwe DO, Olowolafe MO (2014). Assessment of the genetic diversity of African yam bean (Sphenostylis stenocarpa Hochst ex. A. Rich Harms) accessions using amplified fragment length polymorphism (AFLP) markers. African Journal of Biotechnology 13:1850-1858.

Proctor M, Yeo P, Lack A (1996). The natural history of pollination. Harper Collins Publishers, London.

Sahai K (2009). Reproductive biology of two speciess of Canavalia DC (Fabaceae)-a non-convectional wild legume. Flora 204:762-768.

Suso MJ, Rio R (2015). A crop-pollinator inter-play approach to assessing seed production patterns in faba bean under two pollination environments.Euphytica 201:231-251.

Tandon R, Shivanna KR, Mohan-Ram HY (2003). Reproductive biology of Butea monosperma (Fabaceae). Annals of Botany 92:715-723.

Zapata TR, Arroyo MTK (1978).Plant reproductive ecology of a secondary deciduous tropical forest in Venezuela. Biotropica 10:221-230. 